Article

\title{
Covalent Bonding of Si Nanoparticles on Graphite Nanosheets as Anodes for Lithium-Ion Batteries Using Diazonium Chemistry
}

\author{
Yi Zhang ${ }^{1, *(\mathbb{D})}$, Jinghui Ren ${ }^{1}$, Tao Xu ${ }^{1}$, Ailing Feng ${ }^{2}$, Kai Hu ${ }^{1}$, Nengfei Yu ${ }^{1}$, Yingbin Xia ${ }^{1}$, \\ Yusong Zhu ${ }^{1}\left(\mathbb{D}\right.$, Zhengyong Huang ${ }^{3, *}$ and Guanglei $\mathrm{Wu}^{4,5, * \mathbb{D}}$ \\ 1 School of Energy Sciences and Engineering, Nanjing Tech University, Nanjing 211816, China; \\ 1201961108004@njtech.edu.cn (J.R.); zyx7452@njtech.edu.cn (T.X.); 201861108005@njtech.edu.cn (K.H.); \\ yunf@njtech.edu.cn (N.Y.); leslie@njtech.edu.cn (Y.X.); zhuys@njtech.edu.cn (Y.Z.) \\ 2 Institute of Physics \& Optoelectronics Technology, Baoji University of Arts and Sciences, Baoji 721016, China; \\ ailing@mail.xjtu.edu.cn \\ 3 State Key Laboratory of Power Transmission Equipment \& System Security and New Technology, \\ Chongqing University, Chongqing 400040, China \\ 4 Institute of Materials for Energy and Environment, State Key Laboratory of Bio-fibers and Eco-textiles, \\ College of Materials Science and Engineering, Qingdao University, Qingdao 266071, China \\ 5 Key Laboratory of Engineering Dielectrics and Its Application, Ministry of Education, Harbin University of \\ Science and Technology, Harbin 150080, China \\ * Correspondence: zhangy@njtech.edu.cn (Y.Z.); huangzhengyong@cqu.edu.cn (Z.H.); \\ wuguanglei@qdu.edu.cn or wuguanglei@mail.xjtu.edu.cn (G.W.)
}

Received: 23 October 2019; Accepted: 3 December 2019; Published: 6 December 2019

check for updates

\begin{abstract}
Silicon/carbon (Si/C) composite has been proven to be an effective method of enhancing the electrochemical performance of Si-based anodes for lithium-ion batteries (LIBs). However, the practical application of $\mathrm{Si} / \mathrm{C}$ materials in LIBs is difficult because of the weak interaction between Si and C. In this study, we applied two-step diazotization reactions to modify graphite nanosheets (GNs) and Si nanoparticles (Si NPs), yielding a stable Si-Ar-GNs composite. Owing to aryl (Ar) group bonding, Si NPs were dispersed well on the GNs. The as-prepared Si-Ar-GNs composite delivered an initial reversible capacity of $1174.7 \mathrm{mAh} \cdot \mathrm{g}^{-1}$ at a current density of $100 \mathrm{mAh} \cdot \mathrm{g}^{-1}$. Moreover, capacity remained at $727.3 \mathrm{mAh} \cdot \mathrm{g}^{-1}$ after 100 cycles, showing improved cycling performance. This synthesis strategy can be extended to prepare other Si/C anode materials of LIBs.
\end{abstract}

Keywords: silicon; graphite nanosheets; diazotization reaction; anode

\section{Introduction}

Lithium-ion batteries (LIBs) are the energy storage devices that drive today's global portable electronic device market and show great potential for wider applications such as electric vehicles (EVs) because of their high specific energy, long cycle life, lightweight properties, and environmental friendliness [1-5]. However, current LIBs cannot keep pace with the increasing power demands for EVs [6]. LIBs have an anode and a cathode; the two materials exchange lithium ions, which is the key to improving the performance of LIBs. In order to improve the energy density of LIBs, new anode materials must be investigated.

Many groups have spent decades working to develop novel anode materials for LIBs [7-12]. Among these materials, silicon holds great potential as an anode material due to its high theoretical gravimetric capacity of $4200 \mathrm{mAh} \cdot \mathrm{g}^{-1}$, compared with graphite's $372 \mathrm{mAh} \cdot \mathrm{g}^{-1}$, because it is great insert/de-insert many more lithium ions than the graphite in current LIBs. However, after a few 
charge-and-discharge cycles, silicon is prone to fracturing and breaking due to its expansion and contraction during de-alloying/alloying processes [13-17]. These issues can be addressed by designing novel anodes incorporating $\mathrm{Si}$ and $\mathrm{C}$, such as Si/amorphous carbon [18,19], Si/carbon nanotubes [20,21], and Si/graphene composite anodes [22,23], which may offer a high electrical conductivity and a good mechanical flexibility to accommodate $\mathrm{Si}$ volume expansion during the lithiation process.

Graphite nanosheets (GNs) are a kind of two-dimensional (2D) carbon material. Because of their excellent electrical conductivity, GNs have been widely used as electrical conductive filler [24,25]. In our previous papers, we prepared $\mathrm{Ag} / \mathrm{GNs}$ [26] and Ni/GNs composites [27]. We found that GNs have a high specific surface that is beneficial for the deposition of Si nanoparticles (Si NPs). Thus, GNs have great potential to provide a better cycle life for $\mathrm{Si} / \mathrm{C}$ anodes because of their unique structure and high electrical conductivity. However, the basal plane $s p^{2}$ carbon atoms of GNs and Si NPs are weak. It is difficult to deposit Si NPs on the surface of GNs. Diazonium chemistry is an effective method to modify the surface of GNs and improve the binding of GNs and nanoparticles [28]. $p$-phenylenediamine contains two $\mathrm{NH}_{2}$ groups that can result in two diazotization reactions. Thus, we covalented modified GNs with $p$-phenylenediamine, forming $\mathrm{NH}_{2}-\mathrm{Ar}-\mathrm{GNs}$ by diazotization reaction. The resulting $\mathrm{NH}_{2}-\mathrm{Ar}-\mathrm{GNs}$ reacted with $\mathrm{Si}$ to yield a stable $\mathrm{Si}-\mathrm{Ar}-\mathrm{GNs}$ composite by another step diazotization reaction. Owing to Ar group bonding, the as-prepared $\mathrm{Si}-\mathrm{Ar}-\mathrm{GNs}$ composite anode showed better cycling stability compared with the bare Si anode.

\section{Experimental Section}

\subsection{Materials}

The natural graphite powders (400 mesh) were purchased from Nanjing XFNANO Materials Tech Co., Ltd. (Nanjing, China). Si NPs (200 nm) were purchased from Sigma-Aldrich (St. Louis, MO, USA). Other chemicals were provided by Sinopharm Chemical Reagent Co., Ltd. (Shanghai, China).

\subsection{Synthesis of $\mathrm{Si}-\mathrm{Ar}-\mathrm{GNs}$ Composite}

The GNs were prepared as follows. The natural graphite powders were added to a mixed acid containing nitric acid and sulfuric acid $(1: 4, v / v)$ at $25^{\circ} \mathrm{C}$ for one day. The acidized graphites were heated at $1050{ }^{\circ} \mathrm{C}$ for $12 \mathrm{~s}$ in a muffle furnace to prepare expanded graphite. The expanded graphite was stirred in an $80 \%$ aqueous alcohol solution at $25^{\circ} \mathrm{C}$ for one day. Then the mixture was sonicated to break expanded graphite into nanoscale sheets. Finally, the resulting dispersion was filtered, washed, and dried in a freezing vacuum dryer to yield GNs. The schematic illustration of the synthesis of GNs is illustrated in Figure 1.

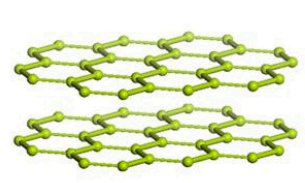

natural graphite

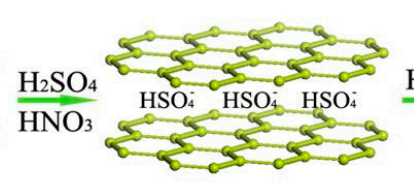

Figure 1. The schematic illustration of graphite nanosheets (GNs) preparation.

A total of $0.1 \mathrm{~g}$ of GNs was immersed in $100 \mathrm{~mL}$ of acetonitrile containing $21 \mathrm{mmol} p$-phenylenediamine, followed by adding $21 \mathrm{mmol}$ sodium nitrite. The mixture was stirred for $12 \mathrm{~h}$ at $25^{\circ} \mathrm{C}$. Then, the mixture was filtered, washed, and dried at $70^{\circ} \mathrm{C}$ for $12 \mathrm{~h}$ to obtain $\mathrm{NH}_{2}-\mathrm{Ar}-\mathrm{GNs}$. The obtained $\mathrm{NH}_{2}-\mathrm{Ar}-\mathrm{GNs}$ were dispersed in $100 \mathrm{~mL}$ of acetonitrile, followed by adding $0.05 \mathrm{~g}$ of Si NPs. Then, 21 mmol of sodium nitrite was added. The mixture reacted for $12 \mathrm{~h}$ at $25^{\circ} \mathrm{C}$. After being filtered, washed, and dried at $70{ }^{\circ} \mathrm{C}$ for $12 \mathrm{~h}$, a Si-Ar-GNs composite was obtained. A schematic illustration of the synthesis of the $\mathrm{Si}-\mathrm{Ar}-\mathrm{GNs}$ composite is illustrated in Figure 2. For comparison, Si NPs and GNs (m ( $\mathrm{Si}) / \mathrm{m}(\mathrm{GNs})=1: 2)$ were ball milled to prepare a Si NPs mixed with GNs (Si/GNs) composite. 


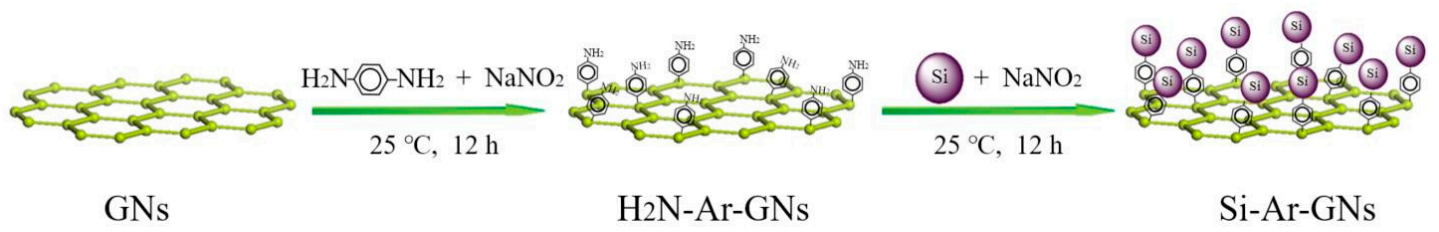

Figure 2. The schematic illustration of Si-Ar-GNs preparation.

\subsection{Characterization}

The phase compositions of GNs were analyzed by X-ray powder diffraction (XRD, Rint-2000, Rigaku) with $\mathrm{Cu} \mathrm{K} \alpha$ radiation. Raman spectra were taken by a Reinishaw Raman (RE01) equipped with a $514 \mathrm{~nm}$ diode laser. FTIR analyses were conducted using a Bruker Vertex 70 spectrometer from 750 to $4250 \mathrm{~cm}^{-1}$ at a resolution of $4 \mathrm{~cm}^{-1}$. The morphologies of the $\mathrm{Si}-\mathrm{Ar}-\mathrm{GNs}$ composite and the Si/GNs composite were observed by scanning electron microscopy (SEM, Quanta 250, FEI Inc., Hillsboro, OR, USA). The internal morphologies of the $\mathrm{Si}-\mathrm{Ar}-\mathrm{GNs}$ composite and the $\mathrm{Si} / \mathrm{GNs}$ composite were studied using a transmission electron microscope (TEM, JEOL, JEM-2100 HT) and HRTEM.

\subsection{Electrochemical Characterization}

Homogeneous slurry was prepared by mixing 80 wt \% of Si-Ar-GNs composite, 10 wt \% of Super-P carbon black, and $10 \mathrm{wt} \%$ of polyacrylic acid (PAA) binder in deionized water. The slurry was then applied to $\mathrm{Cu}$ foil as a current collector and dried in a vacuum oven at $100{ }^{\circ} \mathrm{C}$ for $24.0 \mathrm{~h}$. The thickness of the electrodes was $70 \mu \mathrm{m}$. Coin-type 2025 half-cells were fabricated in an argon-filled glove box (Lab2000, Etelux, China) using the coated $\mathrm{Cu}$ disc as the working electrode, lithium foil as the counter electrode, $1 \mathrm{M} \mathrm{LiPF}_{6}$ in a mixture of diethyl carbonate (DEC) and ethylene carbonate (EC) $(1: 1, v / v)$ as the electrolyte, and Celgard 2320 membrane as the separator. The galvanostatic charge-discharge performance was tested on a battery test system (BT2000, Arbin, USA) from 0.01 to $3.0 \mathrm{~V}$. Cyclic voltammetry (CV) property was tested by an electrochemical station (PGSTAT 302N, Metrohm, Switzerland) in the $0.01-2.0 \mathrm{~V}$ window at a scan rate of $0.2 \mathrm{mV} \mathrm{s}^{-1}$.

\section{Results and Discussion}

To investigate the morphology of the expanded graphite, SEM analysis was carried out. Figure 3 shows SEM images of expanded graphite under different magnifications. Figure 3a shows that the expanded graphite displayed a worm-like morphology. Figure 3b indicates that expanded graphite showed a loosely packed structure that contained multilayered graphite sheets of nanoscale thickness and microscale diameter. Expanded graphite was prepared by the intensive heating of $\mathrm{H}_{2} \mathrm{SO}_{4}-$ graphite intercalation composite. During the synthesis, huge energy led to $\mathrm{H}_{2} \mathrm{SO}_{4}$ decomposition that resulted in a high expansion of graphite. Thus, the expanded graphite formed a loose and porous structure with a high surface area.
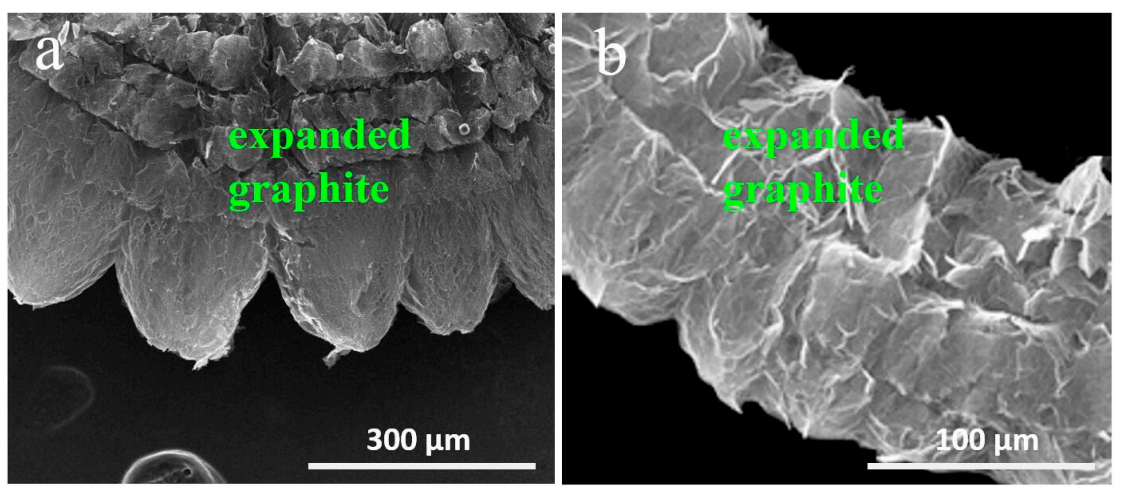

Figure 3. SEM images of expanded graphite: (a) low magnification; (b) high magnification. 
Figure 4 displays SEM images of GNs, Si/GNs composites, and Si-Ar-GNs composites. GNs were made by sonicating the expanded graphite in an aqueous alcohol solution. After sonication, the expanded graphite was peeled to nanoscale sheets with a diameter range of 10-20 $\mu \mathrm{m}$ (Figure 4a). Figure $4 \mathrm{~b}$ shows that the GNs were quite thin, and the thickness was around $30 \mathrm{~nm}$. The surface area of the GNs was $101.2 \mathrm{~m}^{2} \cdot \mathrm{g}^{-1}$, suggesting a high specific surface for Si nanoparticle dispersion. However, the surface carbon atoms of graphite have a weak interaction with particles. It was difficult to deposit Si NPs on the GNs' surface. Figure 4c shows most of the Si NPs of Si/GNs agglomerated in edge areas of GNs. Thus, the surface chemistry of CNs played a vital role in depositing Si NPs. The surface chemistry of GNs and Si NPs yielded a strong chemical bond (phenyl group) between the GNs and Si NPs, forming a uniformly dispersed structure (Figure 4d). To test each component's content of Si-Ar-GNs composite, energy dispersive X-ray (EDX) analyses were conducted. Figure 4e,f shows the SEM and EDX spectrum of the Si-Ar-GNs composite. Two strong peaks were assigned to $\mathrm{C}$ and $\mathrm{Si}$. The composition of $\mathrm{Si}-\mathrm{Ar}-\mathrm{GNs}$ composite calculated from EDX analysis was $67.3 \mathrm{wt} \% \mathrm{C}$ and 32.7 wt \% Si.
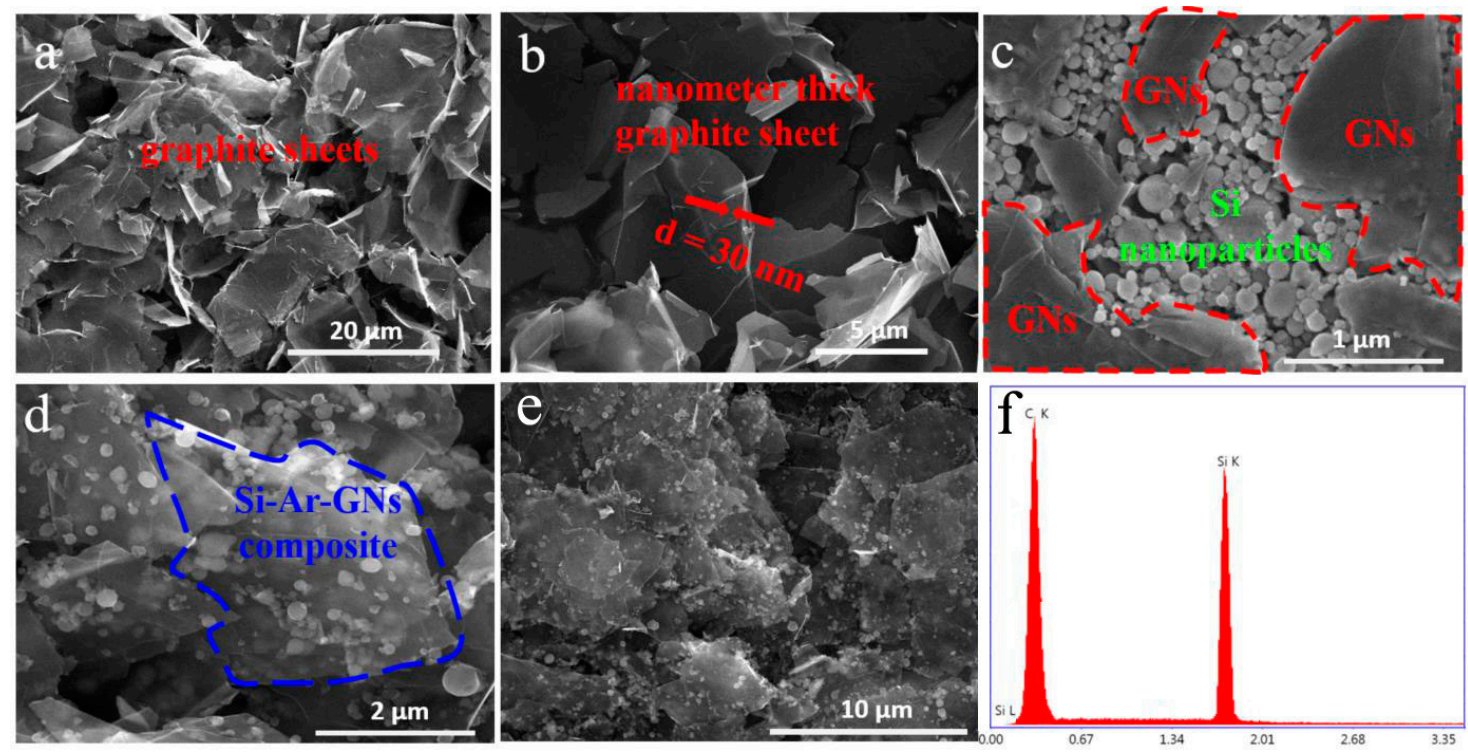

Figure 4. (a,b) SEM images of graphite nanosheets (GNs); (c) SEM image of Si/GNs; (d,e) SEM images of $\mathrm{Si}-\mathrm{Ar}-\mathrm{GNs}$; (f) energy dispersive X-ray (EDX) spectrum of the $\mathrm{Si}-\mathrm{Ar}-\mathrm{GNs}$ composite.

The crystal structure of the GNs was identified using a Raman spectrum as shown in Figure 5a. The peaks in the Raman spectrum at $1345 \mathrm{~cm}^{-1}$ and $1575 \mathrm{~cm}^{-1}$ corresponded to the D-band (defect) and G-band, respectively. The G-band originated from graphitic structures $\left(s p^{2}\right)$, and the D-band arose from $s p^{3}$ carbon and was sensitive to carbon impurities.

The ratio of the integrated area of the D-band to the G-band, $R\left(I_{\mathrm{D}} / I_{\mathrm{G}}\right)$, indicated the degree of carbonization [29,30]. A low $R$ value means a high purity of graphite. The calculated $R$ value of the GNs was 0.04 , reflecting a high degree of graphitization. Figure $5 \mathrm{~b}$ shows the XRD patterns of the GNs and $\mathrm{Si}-\mathrm{Ar}-\mathrm{GNs}$. The diffraction peaks at $26.4^{\circ}$ and $54.4^{\circ}$ can be indexed as the (002) and (004) planes of graphite (JCPDS No. 41-1487) [31], respectively. The peaks at about $28.3^{\circ}, 47.4^{\circ}$, and $56.2^{\circ}$ were assigned to (111), (220), and (311) planes of cubic phase silicon (JCPDS No. 27-1402) [32], respectively. The Si-Ar-GNs was characterized by FTIR spectroscopy (Figure 5c). The FTIR spectrum of $\mathrm{NH}_{2}-\mathrm{Ar}-\mathrm{GNs}$ showed peaks at around 3450,1635, 1489, and $1395 \mathrm{~cm}^{-1}$. The peaks at 3450 and $1635 \mathrm{~cm}^{-1}$ belonged to $\mathrm{N}-\mathrm{H}$ stretching and bending vibration, while peaks at around 1489 and $1395 \mathrm{~cm}^{-1}$ were assigned to $\mathrm{C}=\mathrm{C}$ and $\mathrm{C}-\mathrm{H}$ stretching vibration [33], respectively, indicating that $\mathrm{NH}_{2}-\mathrm{Ar}$ was grafted onto the GNs' surface. After reacting with $\mathrm{Si} \mathrm{NPs}$, the peaks belonging to phenyl retained while peaks assigned to $\mathrm{NH}_{2}$ disappeared, which revealed that $\mathrm{Si}$ NPs were successfully linked to the GNs' surface via a phenyl group. Moreover, a new weak peak at $3440 \mathrm{~cm}^{-1}$ appeared that 
was assigned to the stretching mode of the $\mathrm{Si}-\mathrm{OH}$ bonds. Figure $5 \mathrm{~d}$ shows the Raman spectrum of Si-Ar-GNs. The peaks in the Raman spectrum at $509 \mathrm{~cm}^{-1}$ and $930 \mathrm{~cm}^{-1}$ were typical features of the Si vibration mode [34]. The ratio of the integrated area of D-band to G-band was still low, which meant the surface chemistry of the GNs did not affect the degree of graphitization.
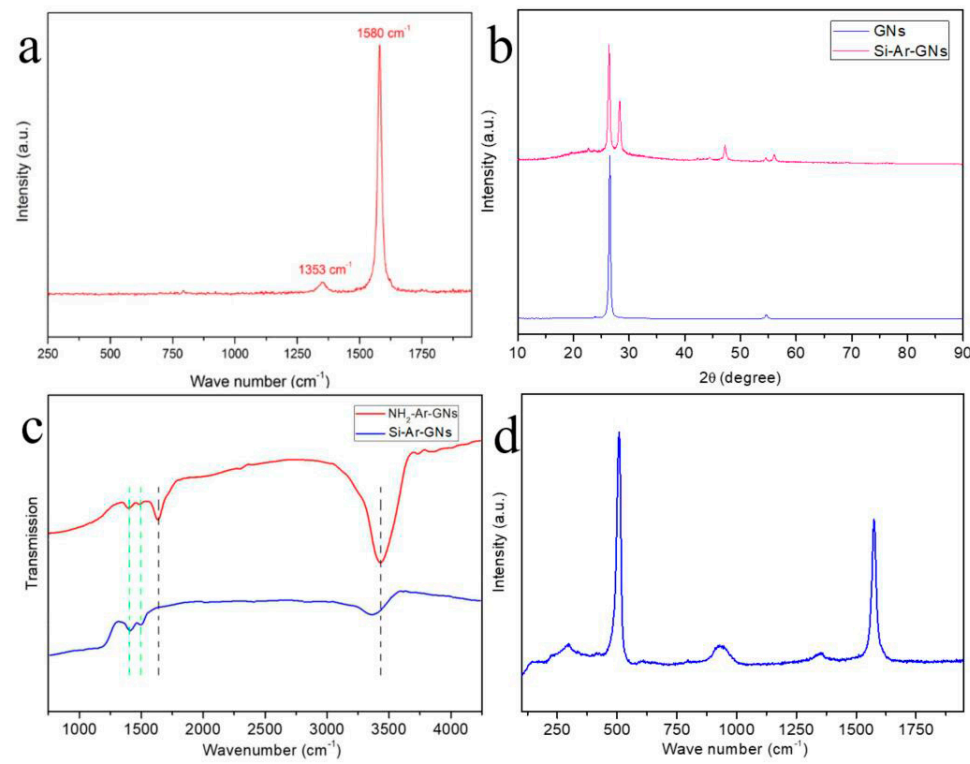

Figure 5. (a) Raman spectrum of GNs; (b) XRD patterns of GNs and Si-Ar-GNs; (c) FTIR spectrum of $\mathrm{H}_{2} \mathrm{~N}-\mathrm{Ar}-\mathrm{GNs}$ and $\mathrm{Si}-\mathrm{Ar}-\mathrm{GNs}$; (d) Raman spectrum of Si-Ar-GNs.

Figure 6 shows TEM, HRTEM, and SAED of Si/GNs and Si-Ar-GNs composites. The agglomeration of Si NPs existed in Si/GNs composites (Figure 6a). For Si-Ar-GNs composites, Si NPs dispersed well on the GNs' surface (Figure 6b). The HRTEM in Figure 6c clearly displayed high crystallinity of Si NPs with a lattice spacing of $0.314 \mathrm{~nm}$, corresponding to a (111) plane of Si [35]. The few-layered structure of graphite can also be clearly observed in the HRTEM. The diffraction in the SAED pattern (Figure 6d) was assigned to the crystal planes of C (002) and Si (111), Si (220), Si (311). All these results agreed well with the SEM images, demonstrating that the Si NPs were strongly fixed on the GNs' surface by phenyl groups.
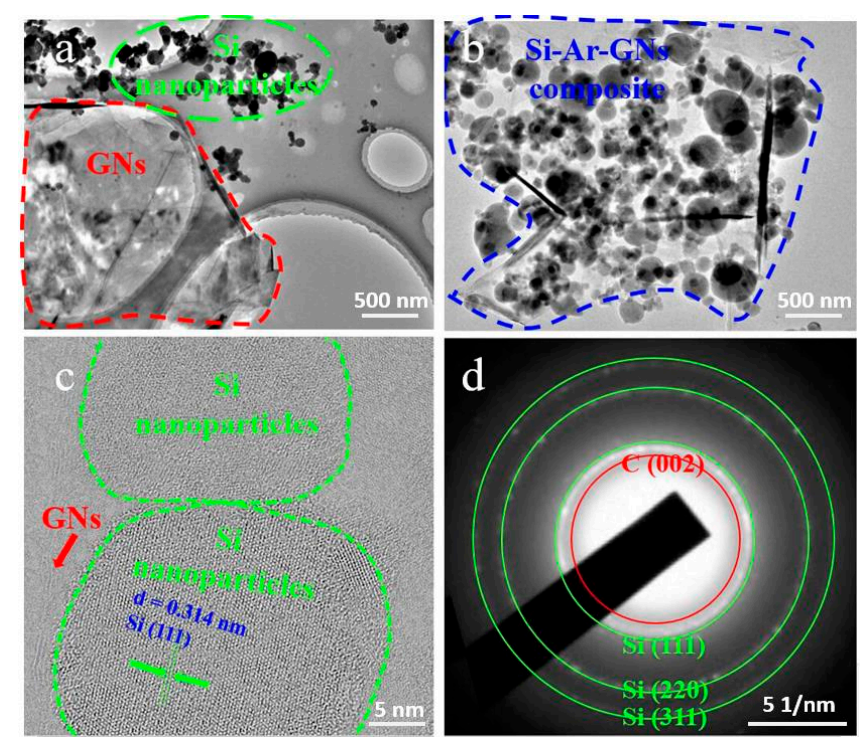

Figure 6. (a) TEM image of a Si/GNs composite; (b) TEM image of a Si-Ar-GNs composite; (c) HRTEM image of a Si-Ar-GNs composite; (d) SAED pattern of Si-Ar-GNs composite. 
The electrochemical performance of Si-Ar-GNs is shown in Figure 7. Figure 7a shows a cyclic voltammetry (CV) curve of a Si-Ar-GNs composite at the second cycle. The CV curve clearly shows that some peaks appeared at $0.25,0.36$, and $0.54 \mathrm{~V}$ during charge. The peak at $0.25 \mathrm{~V}$ was due to the formation of $\mathrm{LiC}_{\mathrm{x}}$ [36]. The peaks at 0.36 and $0.54 \mathrm{~V}$ corresponded to the formation of LixSi [37]. Figure $7 \mathrm{~b}$ shows the charge-discharge curves of the 1st, 2nd, 10th, 20th, 50th, and 100th cycles of Si-Ar-GNs composite electrodes in $0.01-3.0 \mathrm{~V}$ at $100 \mathrm{~mA} \cdot \mathrm{g}^{-1}$, respectively. The discharge curves had a voltage plateau around $0.3 \mathrm{~V}$, corresponding to a reversible reaction from $\mathrm{Si}$ to LixSi [38]. The first discharge and charge capacities of the Si-Ar-GNs composite were $1715.2 \mathrm{mAh} \cdot \mathrm{g}^{-1}$ and $1313.3 \mathrm{mAh} \cdot \mathrm{g}^{-1}$ with a Coulombic efficiency in the first cycle of $76.6 \%$. The irreversible capacity in the first cycle was due to the formation of SEI film. In later cycles the coulombic efficiency rose to above $99.0 \%$, which indicated a good reversibility of the Si-Ar-GNs composite. Figure 7c displays the cycling performance of the Si-Ar-GNs composite and pure $\mathrm{Si}$ anode at $100 \mathrm{~mA} \cdot \mathrm{g}^{-1}$. Pure silicon exhibited a high first reversible capacity of $3132.9 \mathrm{mAh} \cdot \mathrm{g}^{-1}$. However, its capacity quickly decreased to $45.4 \mathrm{mAh} \cdot \mathrm{g}^{-1}$ after 100 cycles. The initial reversible capacity of the Si-Ar-GNs composite was $1174.7 \mathrm{mAh} \cdot \mathrm{g}^{-1}$ and maintained at $727.3 \mathrm{mAh} \cdot \mathrm{g}^{-1}$ at the 100th cycle, corresponding to a capacity retention of $61.9 \%$, which was much higher than that of pure Si (only 1.4\%). Moreover, this result was higher than that of other similar Si/C anodes [39-41]. The improved cycle performance could be ascribed to the strong bonding between Si NPs and CNs, which can effectively buffer the huge volume change. This improvement was studied by electrochemical impedance spectroscopy (EIS) measurements (Figure 7d) on the Si-Ar-GNs composite and pure Si cells. The semicircle on the EIS spectrum of the $\mathrm{Si}-\mathrm{Ar}-\mathrm{GNs}$ composite was smaller than that on the spectrum of pure $\mathrm{Si}$, indicating that the $\mathrm{Si}-\mathrm{Ar}-\mathrm{GNs}$ composite had a lower charge transfer resistance.
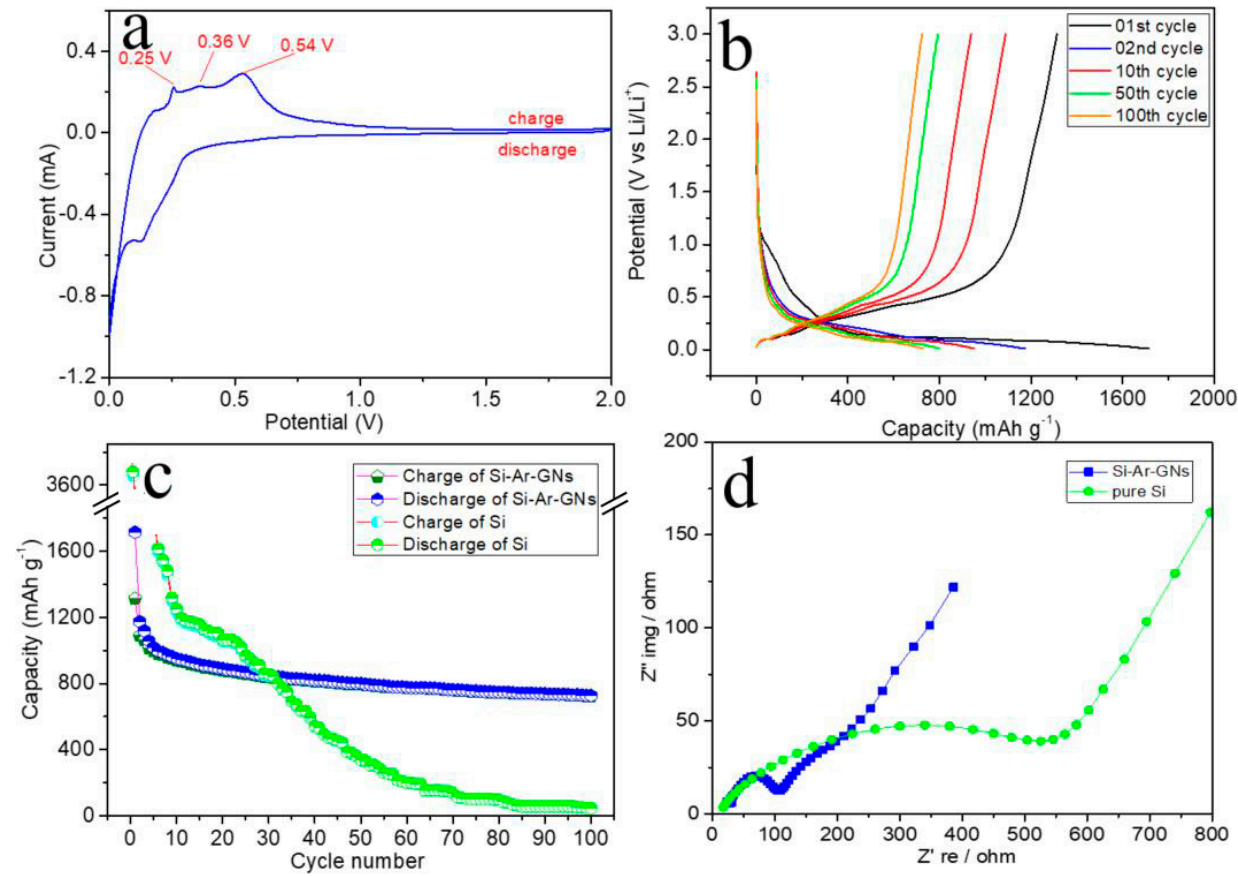

Figure 7. (a) Cyclic voltammetry $(\mathrm{CV})$ of the $\mathrm{Si}-\mathrm{Ar}-\mathrm{GNs}$ composite electrode at the scan rate of $0.2 \mathrm{mV} \cdot \mathrm{s}^{-1}$; (b) galvanostatic charge/discharge profiles of the Si-Ar-GNs composite; (c) cycling performance of pure Si and Si-Ar-GNs composites; (d) electrochemical impedance spectroscopy (EIS) of the $\mathrm{Si}-\mathrm{Ar}-\mathrm{GNs}$ composite and pure Si.

The improvement of the capacity retention of the $\mathrm{Si}-\mathrm{Ar}-\mathrm{GNs}$ composite could be ascribed to the following effects. First, owing to Ar group bonding, Si NPs can disperse well on GNs and avoid aggregation during cycling processes. To study this banding effect, the morphologies of the $\mathrm{Si}-\mathrm{Ar}-\mathrm{GNs}$ composite after 100 cycles was examined. SEM images (Figure 8a,b) show that Si NPs still remain on the 
GNs' surface without aggregation, which means that the surface chemistry of the GNs and Si NPs was effective. Second, GNs have good mechanical flexibility that can accommodate the volume expansion of Si during lithiation process. Third, GNs with high electrical conductivity offer an effective electron transfer path, which could promote electron transfer during the lithiation and delithiation processes.
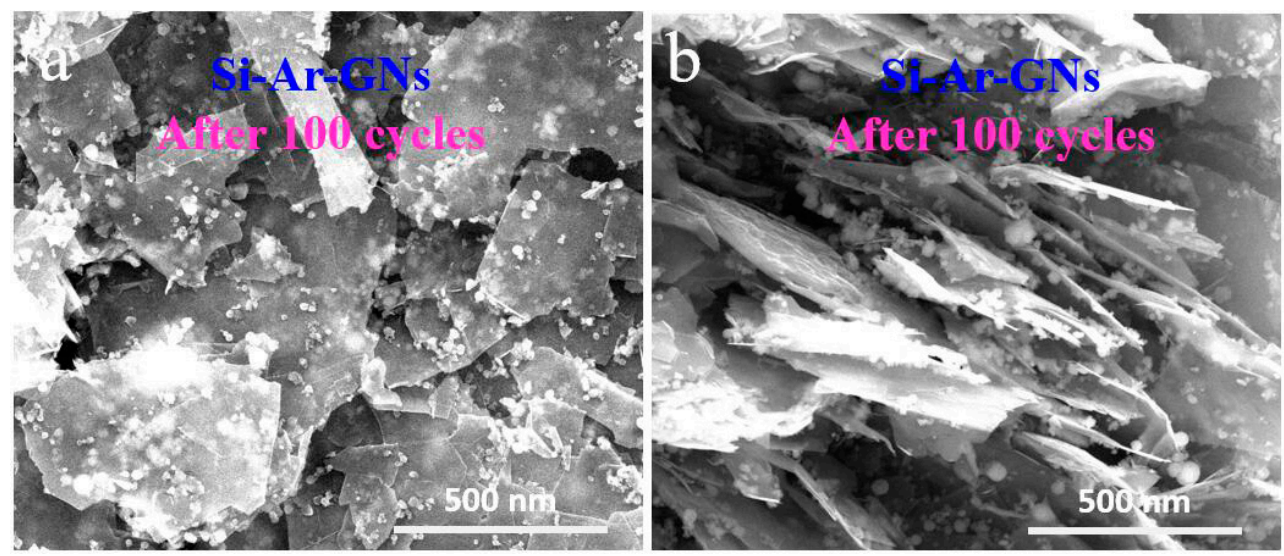

Figure 8. SEM images of the Si-Ar-GNs composite after 100 cycles: (a) top view; (b) side view.

\section{Conclusions}

In summary, Si-Ar-GNs composites were successfully prepared via a two-step diazotization reaction. This method made use of the chemical functions of GNs and Si NPs to yield a covalent bond (Ar group) between GNs and Si NPs. Thus, Si NPs were uniformly coated on the GNs' surface. The covalent bond avoided Si NPs aggregation during cycling processes, and the GNs accommodated the large volume changes of Si NPs, thus improving the cycling stability of the anode. The Si-Ar-GNs composite delivered an initial reversible capacity of $1174.7 \mathrm{mAh} \cdot \mathrm{g}^{-1}$ at a current density of $100 \mathrm{~mA} \cdot \mathrm{g}^{-1}$. A capacity of $727.3 \mathrm{mAh} \cdot \mathrm{g}^{-1}$ was obtained at $100 \mathrm{~mA} \cdot \mathrm{g}^{-1}$ for $100 \mathrm{cycles}$, which was higher than that of pure Si (only $45.4 \mathrm{mAh} \cdot \mathrm{g}^{-1}$ ) and other similar Si/C anodes. The electrochemical performances suggest that the Si-Ar-GNs composite is an ideal anode material for LIBs. Our work provides a simple surface chemistry method to improve the cycling performance of $\mathrm{Si} / \mathrm{C}$ anode materials.

Author Contributions: Writing-review and editing, Y.Z.; data curation, J.R.; investigation, T.X.; resources, A.F.; validation, K.H.; software, N.Y.; formal analysis, Y.X.; validation, Y.Z.; funding acquisition, Z.H.; supervision, G.W.

Funding: This work was funded by the National Key R\&D Program of China (2017YFF0210703), the National Nature Science Foundation of China $(51702157,51707016,51801001,51407134,21603103)$, the China Postdoctoral Science Foundation (2017M611795, 2018T110944, 2016M590619), the Natural Science Foundation of Colleges and Universities of Jiangsu Province in China (17KJB150022), Provincial Key Research and Development Program of Shaanxi (2019GY-197), Key Project of Baoji University of Arts and Sciences (ZK2018051), the Natural Science Foundation of Shandong Province (ZR2019YQ24), Key Laboratory of Engineering Dielectrics and Its Application (Harbin University of Science and Technology), Ministry of Education (No.KFZ1803) and Qingchuang Talents Induction Program of Shandong Higher Education Institution (Research and Innovation Team of Structural-Functional Polymer Composites). And the APC was funded by the National Nature Science Foundation of China, grant number 51707016.

Acknowledgments: This work was supported by the National Key R\&D Program of China (2017YFF0210703), the National Nature Science Foundation of China (51702157, 51707016, 51801001, 51407134, 21603103), the China Postdoctoral Science Foundation (2017M611795, 2018T110944, 2016M590619), the Natural Science Foundation of Colleges and Universities of Jiangsu Province in China (17KJB150022), Provincial Key Research and Development Program of Shaanxi (2019GY-197), Key Project of Baoji University of Arts and Sciences (ZK2018051), the Natural Science Foundation of Shandong Province (ZR2019YQ24), Key Laboratory of Engineering Dielectrics and Its Application (Harbin University of Science and Technology), Ministry of Education (No.KFZ1803) and Qingchuang Talents Induction Program of Shandong Higher Education Institution (Research and Innovation Team of Structural-Functional Polymer Composites).

Conflicts of Interest: The authors declare no conflicts of interest. 


\section{References}

1. Dunn, B.; Kamath, H.; Tarascon, J.M. Electrical energy storage for the grid: A battery of choices. Science 2011, 334, 928-935. [CrossRef] [PubMed]

2. Goodenough, J.B.; Kim, Y. Challenges for rechargeable Li batteries. Chem. Mater. 2009, 22, 587-603. [CrossRef]

3. Zhang, Y.; Zhang, C.; Feng, Y.; Zhang, T.; Chen, Q.; Chi, Q.; Liu, L.; Li, G.; Cui, Y.; Wang, X.; et al. Excellent energy storage performance and thermal property of polymer-based composite induced by multifunctional one-dimensional nanofibers oriented in-plane direction. Nano Energy 2019, 56, 138-150. [CrossRef]

4. Scrosati, B.; Hassoun, J.; Sun, Y. Lithium-ion batteries. In a look into the future. Energy Environ. Sci. 2011, 4, 3287-3295. [CrossRef]

5. Yuan, L.X.; Wang, Z.H.; Zhang, W.X.; Hu, X.L.; Chen, J.T.; Huang, Y.H.; Goodenough, J.B. Development and challenges of $\mathrm{LiFePO}_{4}$ cathode material for lithium-ion batteries. Energy Environ. Sci. 2011, 4, $269-284$. [CrossRef]

6. Li, J.; Zhao, H.; Wang, J.; Li, N.; Wu, M.; Zhang, Q.; Du, Y. Interplanar space-controllable carboxylate pillared metal organic framework ultrathin nanosheet for superhigh capacity rechargeable alkaline battery. Nano Energy 2019, 62, 876-882. [CrossRef]

7. Vernardou, D.; Kazas, A.; Apostolopoulou, M.; Katsarakis, N.; Koudoumas, E. Cationic effect on the electrochemical characteristics of the hydrothermally grown manganese dioxide. J. Electron. Mater. 2017, 46, 2232-2240. [CrossRef]

8. Wu, G.; Jia, Z.; Cheng, Y.; Zhang, H.; Zhou, X.; Wu, H. Easy synthesis of multi-shelled ZnO hollow spheres and their conversion into hedgehog-like $\mathrm{ZnO}$ hollow spheres with superior rate performance for lithium ion batteries. Appl. Surf. Sci. 2019, 464, 472-478. [CrossRef]

9. Huang, Y.; Yang, H.; Zhang, Y.; Zhang, Y.; Wu, Y.; Tian, M.; Chen, P.; Robert, T.; Ma, Y.; Wu, T.; et al. A safe and fast-charging lithium-ion battery anode using MXene supported $\mathrm{Li}_{3} \mathrm{VO}_{4}$. J. Mater. Chem. A 2019, 7, 11250-11256. [CrossRef]

10. Wu, G.; Wu, H.; Wang, K.; Zheng, C.; Wang, Y.; Feng, A. Facile synthesis and application of multi-shelled $\mathrm{SnO}_{2}$ hollow spheres in lithium ion battery. RSC Adv. 2016, 6, 58069-58076. [CrossRef]

11. Wu, X.; Huang, B.; Wang, Q.; Wang, Y. High energy density of two-dimensional MXene/NiCo-LDHs interstratification assembly electrode: Understanding the role of interlayer ions and hydration. Chem. Eng. J. 2020, 380, 122456. [CrossRef]

12. Wu, H.; Wang, Y.; Zheng, C.; Zhu, J.; Wu, G.; Li, X. Multi-shelled NiO hollow spheres: Easy hydrothermal synthesis and Lithium storage performances. J. Alloys Compd. 2016, 685, 8-14. [CrossRef]

13. Wang, K.; Tan, Y.; Li, P.; Xue, B.; Sun, J. Facile synthesis of double layer constrained micron-sized porous $\mathrm{Si} / \mathrm{SiO}_{2} / \mathrm{C}$ composites for lithium ion battery anodes. ACS Appl. Mater. Interfaces 2019, 11, 37732-37740. [CrossRef] [PubMed]

14. Wu, J.; Liu, J.; Wang, Z.; Gong, X.; Wang, Y. A new design for Si wears double jackets used as a high-performance lithium-ion battery anode. Chem. Eng. J. 2019, 370, 565-572. [CrossRef]

15. Zhang, Y.; Hu, K.; Ren, J.; Wu, Y.; Yu, N.; Feng, A.; Zhuang, Z.; Jia, Z.; Wu, G. Sandwich-like Si/SiC/nanographite sheet as high performance anode for lithium-ion batteries. Dalton Trans. 2019, 48, 17683-17690. [CrossRef]

16. Ouyang, Y.; Zhu, X.; Li, F.; Lai, F.; Wu, Y.; Miao, Y.E.; Liu, T. Silicon@nitrogen-doped porous carbon fiber composite anodes synthesized by an in-situ reaction collection strategy for high-performance lithium-ion batteries. Appl. Surf. Sci. 2019, 475, 211-218. [CrossRef]

17. Zhang, Y.; Zhu, Y.; Fu, L.; Meng, J.; Yu, N.; Wang, J.; Wu, Y. Si/C composites as negative electrode for high energy lithium ion batteries. Chin. J. Chem. 2017, 35, 21-29. [CrossRef]

18. Huang, X.; Sui, X.; Yang, H.; Ren, R.; Wu, Y.; Guo, X.; Chen, J. HF-free synthesis of Si/C yolk/shell anodes for lithium-ion batteries. J. Mater. Chem. A 2018, 6, 2593-2599. [CrossRef]

19. Zhou, X.; Ren, Y.; Yang, J.; Ding, J.; Zhang, J.; Hu, T.; Tang, J. Si nanoflake-assembled blocks towards high initial coulombic efficiency anodes for lithium-ion batteries. Chem. Commun. 2018, 54, 12214-12217. [CrossRef]

20. Su, W.; Liang, Y.; Zuo, Y.; Tang, Y. A facile in situ synthesis of SiC\&Si@CNT composite 3D frameworks as an anode material for lithium-ion batteries. Dalton Trans. 2019, 48, 12964-12973.

21. Zhang, Y.; Hu, K.; Zhou, Y.; Xia, Y.; Yu, N.; Wu, G.; Zhu, Y.; Wu, Y.; Huang, H. A facile, one-step synthesis of silicon/silicon carbide/carbon nanotube nanocomposite as a cycling-stable anode for lithium ion batteries. Nanomaterials 2019, 9, 1624. [CrossRef] [PubMed] 
22. Kim, S.; Jeong, Y.K.; Wang, Y.; Lee, H.; Choi, J.W. A “Sticky” Mucin-Inspired DNA-Polysaccharide Binder for Silicon and Silicon-Graphite Blended Anodes in Lithium-Ion Batteries. Adv. Mater. 2018, 30, 1707594. [CrossRef] [PubMed]

23. Zhang, Y.; Jiang, Y.; Li, Y.; Li, B.; Li, Z.; Niu, C. Preparation of nanographite sheets supported Si nanoparticles by in situ reduction of fumed $\mathrm{SiO}_{2}$ with magnesium for lithium ion battery. J. Power Sources 2015, 281, 425-431. [CrossRef]

24. Chen, G.; Weng, W.; Wu, D.; Wu, C. PMMA/graphite nanosheets composite and its conducting properties. Eur. Polym. J. 2003, 39, 2329-2335. [CrossRef]

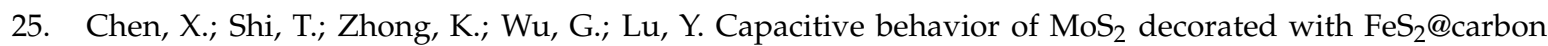
nanospheres. Chem. Eng. J. 2020, 379, 122240.

26. Zhang, Y.; Qi, S.; Wu, X.; Duan, G. Electrically conductive adhesive based on acrylate resin filled with silver plating graphite nanosheet. Synth. Met. 2011, 161, 516-522. [CrossRef]

27. Zhang, Y.; Qi, S.; Zhang, F.; Yang, Y.; Duan, G. Preparation and magnetic properties of polymer magnetic composites based on acrylate resin filled with nickel plating graphite nanosheets. Appl. Surf. Sci. 2011, 258, 732-737. [CrossRef]

28. Yang, S.; Li, G.; Zhu, Q.; Pan, Q. Covalent binding of Si nanoparticles to graphene sheets and its influence on lithium storage properties of Si negative electrode. J. Mater. Chem. 2012, 22, 3420-3425. [CrossRef]

29. Kaniyoor, A.; Baby, T.T.; Ramaprabhu, S. Graphene synthesis via hydrogen induced low temperature exfoliation of graphite oxide. J. Mater. Chem. 2010, 20, 8467-8469. [CrossRef]

30. Sun, G.; Li, X.; Qu, Y.; Wang, X.; Yan, H.; Zhang, Y. Preparation and characterization of graphite nanosheets from detonation technique. Mater. Lett. 2008, 62, 703-706. [CrossRef]

31. Li, Y.; Tang, L.; Li, J. Preparation and electrochemical performance for methanol oxidation of Pt/graphene nanocomposites. Electrochem. Commun. 2009, 11, 846-849. [CrossRef]

32. Xiao, W.; Jin, X.; \& Chen, G.Z. Up-scalable and controllable electrolytic production of photo-responsive nanostructured silicon. J. Mater. Chem. A 2013, 1, 10243-10250. [CrossRef]

33. Du, C.; Chen, M.; Wang, L.; Yin, G. Covalently-functionalizing synthesis of Si@C core-shell nanocomposites as high-capacity anode materials for lithium-ion batteries. J. Mater. Chem. 2011, 21, 15692-15697. [CrossRef]

34. Zeng, X.B.; Liao, X.B.; Wang, B.; Dai, S.T.; Xu, Y.Y.; Xiang, X.B.; Hu, Z.H.; Diao, H.W.; Kong, G.L. Optical properties of boron-doped Si nanowires. J. Cryst. Growth 2004, 265, 94-98. [CrossRef]

35. Zhang, X.Y.; Zhang, L.D.; Meng, G.W.; Li, G.H.; Jin-Phillipp, N.Y.; Phillipp, F. Synthesis of ordered single crystal silicon nanowire arrays. Adv. Mater. 2001, 13, 1238-1241. [CrossRef]

36. Park, M.S.; Lee, Y.J.; Rajendran, S.; Song, M.S.; Kim, H.S.; Lee, J.Y. Electrochemical properties of Si/Ni alloy-graphite composite as an anode material for Li-ion batteries. Electrochim. Acta 2005, 50, 5561-5567. [CrossRef]

37. Fan, X.; Zou, L.; Zheng, Y.P.; Kang, F.Y.; Shen, W.C. Electrospinning preparation of nanosilicon/disordered carbon composite as anode materials in li-ion battery. Electrochem. Solid-State Lett. 2009, 12, A199-A201. [CrossRef]

38. Ren, Y.; Ding, J.; Yuan, N.; Jia, S.; Qu, M.; Yu, Z. Preparation and characterization of silicon monoxide/graphite/carbon nanotubes composite as anode for lithium-ion batteries. J. Solid State Electrochem. 2012, 16, 1453-1460. [CrossRef]

39. Ji, L.; Zhang, X. Evaluation of Si/carbon composite nanofiber-based insertion anodes for new-generation rechargeable lithium-ion batteries. Energy Environ. Sci. 2010, 3, 124-129. [CrossRef]

40. Zhou, X.; Liu, Y.; Du, C.; Ren, Y.; Mu, T.; Zuo, P.; Gao, Y. Polyaniline-encapsulated silicon on three-dimensional carbon nanotubes foam with enhanced electrochemical performance for lithium-ion batteries. J. Power Sources 2018, 381, 156-163. [CrossRef]

41. Tao, H.; Xiong, L.; Zhu, S.; Yang, X.; Zhang, L. Flexible binder-free reduced graphene oxide wrapped $\mathrm{Si} /$ carbon fibers paper anode for high-performance lithium ion batteries. Int. J. Hydrogen Energy 2016, 41, 21268-21277. [CrossRef]

(C) 2019 by the authors. Licensee MDPI, Basel, Switzerland. This article is an open access article distributed under the terms and conditions of the Creative Commons Attribution (CC BY) license (http://creativecommons.org/licenses/by/4.0/). 